\title{
Influence of pre-existing hypertension on neuroendocrine and cardiovascular changes evoked by chronic stress in female rats
}

\author{
Jonas O. Vieira ${ }^{\mathrm{a}, \mathrm{b}}$, Josiane O. Duarte ${ }^{\mathrm{a}, \mathrm{b}}$, Willian Costa-Ferreira ${ }^{\mathrm{a}, \mathrm{b}}$, Carlos C. Crestani ${ }^{\mathrm{a}, \mathrm{b}, *}$ \\ ${ }^{a}$ Laboratory of Pharmacology, School of Pharmaceutical Sciences, UNESP - Univ Estadual Paulista, UNESP, Araraquara, SP, Brazil \\ ${ }^{\mathrm{b}}$ Joint UFSCar-UNESP - Univ Estadual Paulista Graduate Program in Physiological Sciences, São Carlos, SP, Brazil
}

\section{A R T I C L E I N F O}

\section{Keywords:}

Chronic variable stress

Restraint stress

Autonomic activity

Glucocorticoids

Female

SHR

\begin{abstract}
A B S T R A C T
This study investigated neuroendocrine, autonomic, and cardiovascular changes evoked by daily exposure to the same type of stressor (homotypic) or different aversive stressor stimuli (heterotypic) in 60-days-old female normotensive Wistar rats and female spontaneously hypertensive rats (SHR). Both strains of rats were exposed for 10 consecutive days to either the homotypic stressor repeated restraint stress (RRS) or the heterotypic stressor chronic unpredictable stress (CUS). As expected, SHR had higher baseline blood pressure values and impaired baroreflex activity in relation to normotensive animals. Besides, SHR presented higher plasma corticosterone levels and decreased thymus weight. Both RRS and CUS increased baseline plasma corticosterone concentration and decreased body weight gain in both normotensive and SHR rats. In addition, both stress protocols caused hypertrophy of adrenal glands in normotensive rats. Regarding the cardiovascular effects, RRS increased basal heart rate in both rat strains, which was mediated by an increase in sympathetic tone to the heart. Besides, RRS increased baroreflex-mediated tachycardia in SHR animals, while CUS increased cardiac parasympathetic activity and pacemaker activity in normotensive rats. Taken together, these results indicate a stress type-specific effect, as identified by a vulnerability of both strains to the deleterious cardiovascular effects evoked by the homotypic stressor and a resilience to the impact of the heterotypic stressor. Vulnerability of hypertensive rats was evidenced by the absence of CUS-evoked adaptive cardiovascular responses and an increase of baroreflex tachycardia in SHR animals subjected to RRS. The somatic and HPA axis changes were overall independent of the chronic stress regimen and pre-existing hypertension.
\end{abstract}

\section{Introduction}

Clinical and preclinical studies have indicated that the complications related to stress are determined by characteristics of the aversive stimulus, such as type, duration, frequency, controllability, and intensity (Crestani, 2016; Koolhaas et al., 2011; Steptoe and Kivimäki, 2012). The influence of predictability on animal models has been investigated by comparing the effects of chronic stressors involving daily exposure to the same type of aversive stimuli (i.e., homotypic/predictable) versus different stressors (i.e., heterotypic/unpredictable) (Crestani, 2016). These studies have used the repeated restraint stress (RRS) as a homotypic stressor and the chronic unpredictable stress (CUS) as a heterotypic stressor (Crestani, 2016). Studies comparing the impact of RRS versus CUS have demonstrated that the latter induces more severe changes on somatic parameters (e.g., adrenal hypertrophy and thymic involution), hypothalamic-pituitary-adrenal (HPA) axis activity, and anxiety- and depression-like behaviors (Costa-Ferreira et al., 2016; Haile et al., 2001; Magariños and McEwen, 1995; Marin et al., 2007; Pastor-Ciurana et al., 2014). Differences in impact of CUS and RRS on cardiovascular function are less clear. Indeed, studies comparing these two chronic stressors have reported similar mild hypertension, resting tachycardia, increase in cardiac sympathetic activity, and baroreflex impairment following exposure to either stressor (Costa-Ferreira et al., 2016; Duarte et al., 2015; Vieira et al., 2018).

The impact of stress on physiological and psychological processes is also determined by individual characteristics. In this sense, pre-existing cardiovascular complications have been proposed as a factor affecting the impact of stress. Indeed, previous studies documented that hypertensive and normotensive individuals react differently to stressful events. For instance, hypertensive subjects react more intensely to stress than their normotensive counterparts (Al'Absi et al., 1994; Garafova et al., 2014; Lenders et al., 1989; Matsukawa et al., 1991;

\footnotetext{
* Corresponding author at: Laboratory of Pharmacology, Department of Natural Active Principles and Toxicology, School of Pharmaceutical Sciences, UNESP Univ Estadual Paulista, Rodovia Araraquara-Jau Km 01 s/n, 14800-903, Araraquara, SP, Brazil.

E-mail address: crestani@fcfar.unesp.br (C.C. Crestani).
} 
Palatini et al., 2011). Accordingly, preclinical studies also identified that spontaneously hypertensive rats (SHR) - a widely used hypertension model (Trippodo and Frohlich, 1981) - exhibit exacerbated neuroendocrine and behavioral responses to various aversive stimuli when compared to normotensive rats (Djordjevic et al., 2007; Imaki et al., 1998; Roman et al., 2004; van den Buuse et al., 2001). Sympathetic activation and increase of blood pressure and heart rate (HR) caused by various aversive stimuli are also more pronounced in SHR animals (Casto and Printz, 1990; McCarty, 1983; McDougall et al., 2005, 2000; van den Buuse et al., 2001).

The above-mentioned findings indicate a hyper-responsiveness of physiological and behavioral responses during acute sessions of stress in hypertensive animals and humans. Nevertheless, the impact of hypertension on dysfunctions evoked by chronic stressors is still poorly understood. Previous studies comparing normotensive and SHR rats reported either increased baseline blood pressure selectively in the latter (Bernatova et al., 2010) or absence of effect in both strains (Slezak et al., 2014) following exposure to chronic crowding stress. Besides, increased blood pressure in both normotensive and SHR rats was reported following exposure to colony social stress (Toot et al., 2011). Nevertheless, the influence of hypertension in other cardiovascular-related changes evoked by chronic stress such as autonomic imbalance, resting tachycardia, and baroreflex impairment has never been evaluated. Furthermore, evidence of the impact of either CUS or RRS on cardiovascular function of SHR animals is missing. Finally, although evidence of sex-related differences in cardiovascular function (Dubey, 2002) and cardiovascular and neuroendocrine responses to acute stressors (Anishchenko et al., 2007; Eikelis and Van Den Buuse, 2000; Kudielka and Kirschbaum, 2005), the majority of experimental studies have investigated the impact of chronic stressors in male animals. Therefore, our purpose in the present study was to investigate neuroendocrine, autonomic, and cardiovascular changes caused by the exposure to either RRS or CUS in female SHR and normotensive rats.

\section{Material and methods}

\subsection{Animals}

Thirty-three female normotensive Wistar rats (11/experimental group) and twenty-six female SHR rats ( 9 control, 10 RRS, and 7 CUS) 60-days-old were used in the present study. Animals were obtained from the animal breeding facility of the Institute of Biomedical Science/ University of São Paulo (São Paulo, SP, Brazil). All animals were housed in collective plastic cages $(41 \times 34 \times 16 \mathrm{~cm})(3-4$ rats/cage) in a temperature-controlled room at $24^{\circ} \mathrm{C}$ in the Animal Facility of the Laboratory of Pharmacology-UNESP. They were kept under a 12:12 h light-dark cycle (lights on between 7:00 $\mathrm{h}$ and 19:00 $\mathrm{h}$ ) with free access to water and standard laboratory food. Housing conditions and experimental procedures were carried out following protocols approved by the Ethical Committee for Use of Animal of the School of Pharmaceutical Sciences/São Paulo State University, which complies with Brazilian and international guidelines for animal use and welfare.

\subsection{Chronic stress regimens}

The chronic stress regimens were based in protocols previously described by our group (Duarte et al., 2015; Vieira et al., 2018). Therefore, RRS was chosen as a homotypic stressor, whereas CUS was used as a heterotypic stressor. The animals of RRS group were restrained in opaque plastic cylinders $(15 \mathrm{~cm}$ length and $5.5 \mathrm{~cm}$ internal diameter) for $1 \mathrm{~h}$ daily starting at 10:00 a.m. for 10 consecutive days. The CUS protocol consisted of exposure to different stressors in a variable schedule for 10 consecutive days, accordingly to protocol described in Duarte et al (2015). The stressors used in the CUS included: 1) restraint stress (60 min); 2) humid sawdust (overnight or all day); 3 ) cold $\left(4{ }^{\circ} \mathrm{C}\right)$ or room temperature isolation housing; 4) food/water deprivation (overnight); 5) swim stress (4 min); 6) lights on overnight; and 7) lights off during day (120-180 min). All stress sessions were performed in an adjacent room to the animal facility. The RRS and CUS started simultaneously, and during this period animals of control groups were left undisturbed, except for cleaning the cages and body weight measurements, in the animal facility.

\subsection{Surgical preparation}

Animals were anesthetized with tribromoethanol (250 mg/kg, i.p.) and a polyethylene cannula (a $4 \mathrm{~cm}$ segment of PE-10 heat-bound to a $13 \mathrm{~cm}$ segment of PE-50) (Clay Adams, Parsippany, NJ, USA) filled with a solution of heparin (50 UI/ml, Hepamax-S ${ }^{\circledast}$, Blausiegel, Cotia, SP, Brazil) diluted in saline $(0.9 \% \mathrm{NaCl})$ was implanted into the abdominal aorta through the femoral artery for cardiovascular recording. A second cannula filled with heparin solution was inserted into the femoral vein for the infusion of drugs. Both catheters were tunneled under the skin and exteriorized on the animal's dorsum. After the surgery, rats received a poly-antibiotic formulation containing streptomycin and penicillin $(560 \mathrm{mg} / \mathrm{ml} / \mathrm{kg}$, i.m.) to prevent infection, and were treated with the non-steroidal anti-inflammatory drug flunixin meglumine $(0.5 \mathrm{mg} / \mathrm{ml} / \mathrm{kg}$, s.c.) for postoperative analgesia.

\subsection{Measurement of cardiovascular parameters}

The cannula implanted into the femoral artery was connected to a pressure transducer (DPT100, Utah Medical Products Inc., Midvale, UT, USA). Pulsatile arterial pressure (PAP) was recorded using an amplifier (Quad Bridge Amp, ML224, ADInstruments, NSW, Australia) and an acquisition board (PowerLab 4/30, ML866/P, ADInstruments, NSW, Australia) connected to a personal computer. Mean (MAP), systolic (SAP), and diastolic (DAP) arterial pressure; as well as HR values were derived from PAP recordings.

\subsection{Assessment of cardiac autonomic activity and intrinsic $H R$}

Cardiac autonomic activity and intrinsic HR were assessed by intravenously administrating the muscarinic receptor antagonist methylatropine $(3 \mathrm{mg} / \mathrm{ml} / \mathrm{kg})$ and the $\beta$-adrenoceptor antagonist propranolol ( $4 \mathrm{mg} / \mathrm{ml} / \mathrm{kg}$ ) (Almeida et al., 2015; Duarte et al., 2015; Vieira et al., 2018). The protocol was performed on two separate days. On the first day, animals in all experimental groups received intravenous administration of methylatropine and propranolol in a random order. The interval of treatment between the drugs was $10 \mathrm{~min}$. Twenty-four hours later, animals were treated with methylatropine and propranolol in the opposite sequence to that performed on the first day.

The parasympathetic activity was determined by analyzing the change in basal HR caused by methylatropine, while the sympathetic activity was obtained from the HR response evoked by propranolol treatment. The intrinsic HR was obtained after combined treatment with propranolol and methylatropine on first and second days, and a mean of the two values was calculated for each animal.

\subsection{Assessment of baroreflex activity}

Baroreflex function was evaluated using the classical pharmacological approach. For this, intravenous infusion of the $\alpha_{1}$-adrenoceptor agonist phenylephrine $(70 \mu \mathrm{g} / \mathrm{ml}$ at $0.4 \mathrm{ml} / \mathrm{min} / \mathrm{kg})$ and the nitric oxide donor sodium nitroprusside $(100 \mu \mathrm{g} / \mathrm{ml}$ at $0.8 \mathrm{ml} / \mathrm{min} / \mathrm{kg})$ was performed using an infusion pump (K.D. Scientific, Holliston, MA, USA) (Crestani et al., 2010; Engi et al., 2016). Phenylephrine evoked incremental pressor response, whereas sodium nitroprusside caused incremental depressor effects. Infusions of vasoactive drugs were randomized, and the second treatment was not realized before cardiovascular parameters returned to control values (interval between infusions was approximately $5 \mathrm{~min}$ ). Infusions lasted for $20-30 \mathrm{~s}$, resulting in the 
injection of a total dose of 9-14 $\mu \mathrm{g} / \mathrm{kg}$ of phenylephrine and $26-40 \mu \mathrm{g} /$ $\mathrm{kg}$ of sodium nitroprusside.

For assessment of baroreflex function, reflex HR changes $(\triangle \mathrm{HR})$ corresponding to MAP changes ( $\triangle \mathrm{MAP}$ ) (each $5 \mathrm{mmHg}$ of $\triangle \mathrm{MAP}$ ) evoked by intravenous infusion of phenylephrine and sodium nitroprusside were plotted to generate sigmoid logistic functions (Crestani et al., 2010; Engi et al., 2016). Analysis of sigmoid curves were characterized by 5 parameters: (i) lower HR plateau $\left(\mathrm{P}_{1}\right.$, in $\left.\mathrm{bpm}\right)$, which is the maximum reflex bradycardia during blood pressure increase; (ii) upper HR plateau $\left(\mathrm{P}_{2}\right.$, in bpm), which is the maximum reflex tachycardia to blood pressure decrease; (iii) HR range (bpm), which is the difference between $\mathrm{P}_{1}$ and $\mathrm{P}_{2}$; (iv) median blood pressure $\left(\mathrm{BP}_{50}, \mathrm{mmHg}\right)$, which is the MAP at $50 \%$ of the HR range; and (v) average gain $(\mathrm{G}, \mathrm{bpm} / \mathrm{mmHg}$ ), which is the average slope of the curves between +1 and -1 standard derivations from $\mathrm{BP}_{50}$ (Crestani et al., 2010; Engi et al., 2016).

\subsection{Plasma corticosterone measurement}

Blood sample $(200 \mu \mathrm{l})$ was collected from the femoral artery cannula for determination of plasma corticosterone concentration. Blood was collected in plastic tubes containing $5 \mu \mathrm{l}$ of heparin $(5000 \mathrm{UI} / \mathrm{ml})$ (Hepamax-S ${ }^{\circledR}$, Blausiegel, Cotia, SP, Brazil). Samples were centrifuged at $2000 \mathrm{~g}$ for $10 \mathrm{~min}$ at $4{ }^{\circ} \mathrm{C}$ and plasma was stored at $-20^{\circ} \mathrm{C}$ until corticosterone assay was carried out.

Plasma corticosterone concentration was measured by radioimmunoassay, as described previously (Sarnyai et al., 1992). Briefly, $20 \mu \mathrm{l}$ of plasma was diluted 50 times with $0.01 \mathrm{M}$ PBS and placed in a water bath at $75^{\circ} \mathrm{C}$ for $1 \mathrm{~h}$ for heat inactivation of corticosteroid binding globulin. One hundred microliters of a solution of antibody and (3 H)-corticosterone (New England Nuclear; Boston, MA, USA) $(10,000-20,000 \mathrm{cpm} / \mathrm{ml})$ was added to each sample, mixed and incubated overnight at $4{ }^{\circ} \mathrm{C}$. Dextran-coated charcoal was used to adsorb free steroid after incubation. Tubes were centrifuged at $2000 \times \mathrm{g}$ for $15 \mathrm{~min}$ at $4^{\circ} \mathrm{C}$, the supernatant from each tube was transferred to scintillation vials and the radioactivity was quantified by liquid scintillation spectrometry. Standard curves were constructed using 25, 50, $100,250,500,750,1000$ and $2000 \mathrm{pg} / 100 \mu \mathrm{l}$ of corticosterone (SigmaAldrich, St. Louis, MO, USA).

\subsection{Drugs and solutions}

Propranolol hydrochloride (Sigma-Aldrich, St. Louis, MO, USA), methylatropine (Sigma-Aldrich), phenylephrine hydrochloride (SigmaAldrich), sodium nitroprusside dihydrate (Sigma-Aldrich), tribromoethanol (Sigma-Aldrich), and urethane (Sigma-Aldrich) were dissolved in saline $\left(0.9 \% \mathrm{NaCl}\right.$ ). Flunixin meglumine (Banamine ${ }^{\circledR}$, Schering-Plough, Cotia, SP, Brazil) and the poly-antibiotic preparation (Pentabiotico $^{\circledast}$, Fort-Dodge, Brazil) were used as provided.

\subsection{Experimental procedures}

Normotensive Wistar rats and SHR were randomly divided into three groups: (i) control, (ii) RRS, and (iii) CUS. The animals of RRS and CUS groups were submitted to daily sessions of stress for 10 consecutive days. At $10^{\text {th }}$ day, after the last session of stress, animals in all experimental groups were subjected to surgical preparation. Since the purpose of the present study was to investigate the enduring changes evoked by chronic stress exposure, the tests were performed $24 \mathrm{~h}$ and $48 \mathrm{~h}$ after the last stress session.

On test days, animals were transferred to the experimental room in their home box and were allowed $60 \mathrm{~min}$ to adapt to experimental room conditions, such as sound and illumination. On the first day, a blood sample $(200 \mu \mathrm{L})$ was collected from the femoral artery cannula before the onset of cardiovascular recording for determination of plasma corticosterone concentration. Then, animals were individually connected to the cardiovascular recording system in the home cage and subjected to at least a 30-minute period of basal cardiovascular recording. In the sequence, randomized intravenous infusions of phenylephrine and sodium nitroprusside were performed for evaluation of baroreflex function. Afterwards, animals received intravenous administration of methylatropine and propranolol in a random order for analysis of cardiac autonomic tone and pacemaker activity. On the second day, animals were treated with methylatropine and propranolol in the opposite sequence to that performed on the first day. Animals were allowed to freely move throughout the cardiovascular recording. At the end of the experiments, animals were euthanized by anesthetic overdose (urethane, $250 \mathrm{mg} / \mathrm{ml} / 200 \mathrm{~g}$ body weight, i.p.) and their heart, both adrenal glands and thymus were removed and weighed.

\subsection{Data analysis}

Data were expressed as mean \pm SEM. Analysis of body weight values was performed using three-way ANOVA, with stress (control, RRS, and CUS) and strain (normotensive vs SHR) as independent factors and time as repeated measurement. The other measures were analyzed using two-way ANOVA, with stress and strain as independent factors. Planned comparisons using the Bonferroni post hoc test were performed after two- and three-way ANOVA to assess specific differences between the experimental groups when ANOVA indicated effect of stress and/or interaction between the factors. When ANOVA identified effect of the factor "stress" without interaction, planned comparisons were carried out to identify specific differences between experimental groups within each strain, but without comparing differences between the strains. Planned comparisons for identification of specific differences between strains for each condition (i.e., control, RRS and CUS) was carried out only when two-way ANOVA identified interaction between the factors. $\mathrm{P}<0.05$ was assumed as significant.

\section{Results}

\subsection{Effects of CUS and RRS in normotensive and SHR rats on somatic parameters and plasma corticosterone concentration}

\subsubsection{Body weight}

Time course analysis of body weight indicated that SHR animals in all experimental groups had lower body weight in relation to respective normotensive groups throughout the period of analysis (control: $\mathrm{P}<0.05$, RRS: $\mathrm{P}<0.05$, CUS: $\mathrm{P}<0.05$ ) (Fig. 1A). Moreover, the RRS $(\mathrm{P}<0.05)$ and CUS $(\mathrm{P}<0.05)$ reduced body weight gain in normotensive females on day 10 , while the reduction of body weight in SHR rats was identified on days 5 (CUS: $\mathrm{P}<0.05$, RRS: $\mathrm{P}<0.05$ ) and 10 (CUS: $\mathrm{P}<0.05$, RRS: $\mathrm{P}<0.05$ ) (Fig. $1 \mathrm{~A}$ ). The three-way ANOVA indicated a significant effect of strain $\left(\mathrm{F}_{(1,53)}=189, \mathrm{P}<0.0001\right)$, stress $\left(\mathrm{F}_{(2,53)}=5, \mathrm{P}>0.009\right)$, and time $\left(\mathrm{F}_{(2,106)}=7, \mathrm{P}<0.001\right)$. Besides, there was a time $\mathrm{x}$ stress interaction $\left(\mathrm{F}_{(} 4,106\right)=6$, $\mathrm{P}<0.0002)$, but without strain $\mathrm{x}$ stress $\left(\mathrm{F}_{(2,53)}=0.1, \mathrm{P}>0.05\right)$ and time $\mathrm{x}$ strain $\left.\left(\mathrm{F}_{(} 2,106\right)=1, \mathrm{P}>0.05\right)$ interactions.

Analysis of body weight change (i.e., difference between the values on first and $10^{\text {th }}$ day of stress protocol) indicated that both RRS and CUS decreased the body weight gain in normotensive (RRS: $\mathrm{P}<0.01$, CUS: $P<0.03$ ) and SHR rats (RRS: $P<0.04$, CUS: $P<0.05$ ) (Fig. 1B). Analysis indicated a significant effect of stress $\left(\mathrm{F}_{(2,53)}=8\right.$, $\mathrm{P}<0.0009)$, but without effect of strain $\left.\left(\mathrm{F}_{(} 1,53\right)=1, \mathrm{P}>0.05\right)$ and strain $\mathrm{x}$ stress interaction $\left(\mathrm{F}_{(2,53)}=0.1, \mathrm{P}>0.05\right)($ Fig. 1B).

\subsubsection{Heart weight}

RRS decreased absolute values of heart weight in SHR rats $(\mathrm{P}<0.05)$, but not in normotensive rats $(\mathrm{P}>0.05)$ (Table 1$)$. Analysis of relative heart weight (heart weight/body weight at $10^{\text {th }}$ day) indicated that SHR rats presented higher values regardless of stress exposure $(\mathrm{P}<0.05)$ (Fig. 1C). The analysis of absolute heart weight 

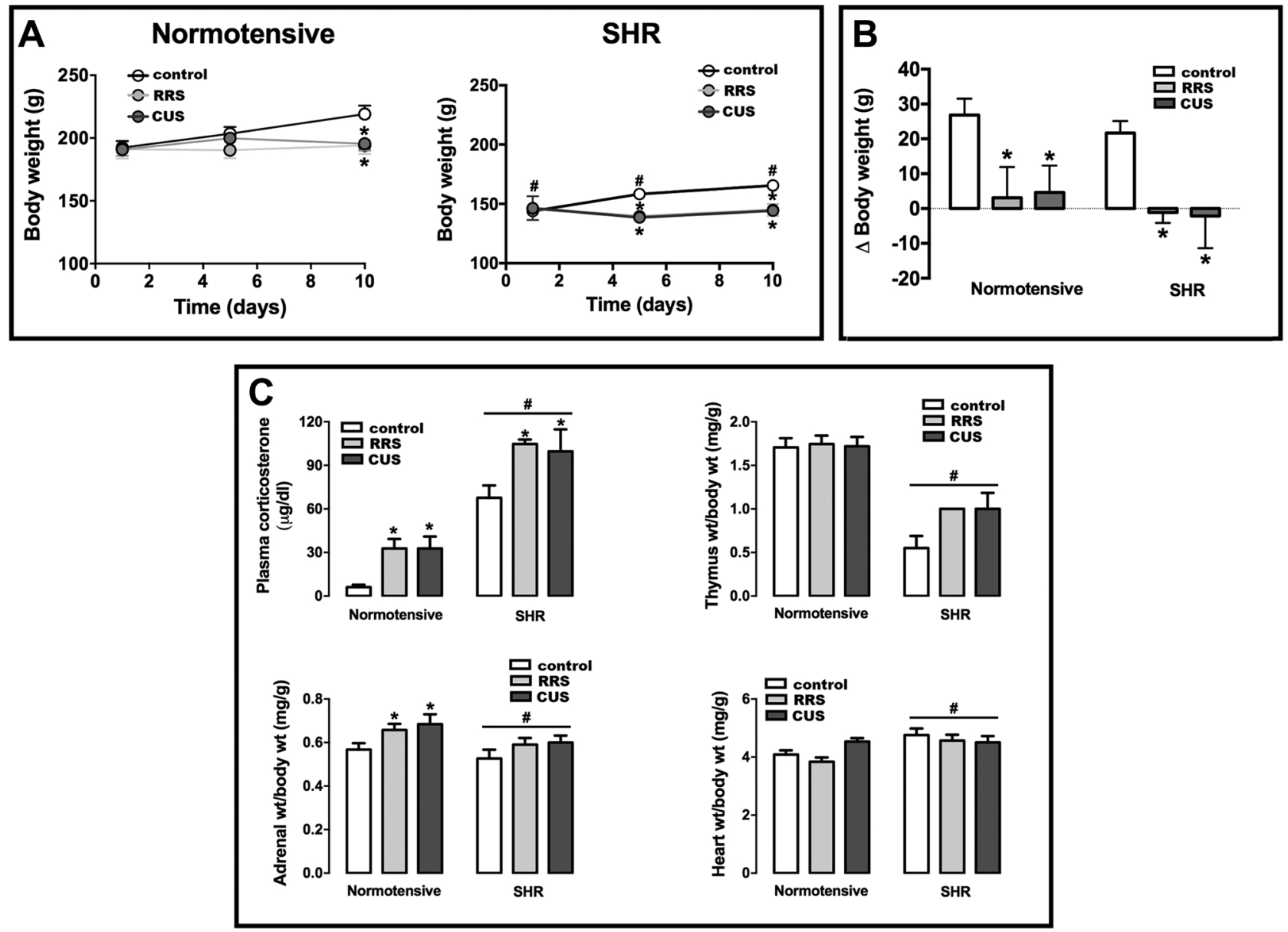

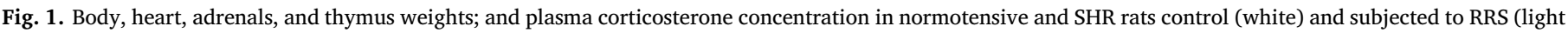

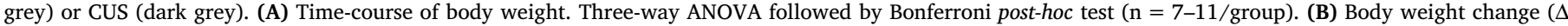

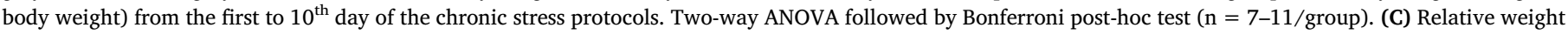

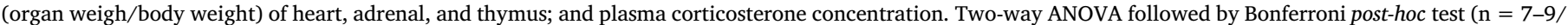
group). The bars/circles in all graphs represent the mean \pm SEM. ${ }^{*} \mathrm{P}<0.05$ vs respective control group, \#P $<0.05$ vs e normotensive groups.

Table 1

Absolute weight of heart, adrenal and thymus in normotensive and SHR rats subjected to repeated restraint stress (RRS) or chronic unpredictable stress (CUS).

\begin{tabular}{llll}
\hline Groups & $\begin{array}{l}\text { Heart } \\
\text { Absolute weight } \\
(m g)\end{array}$ & $\begin{array}{l}\text { Adrenal } \\
\text { Absolute weight } \\
(m g)\end{array}$ & $\begin{array}{l}\text { Thymus } \\
\text { Absolute weight } \\
(m g)\end{array}$ \\
\hline Normotensive & & $120 \pm 8$ & $326 \pm 16$ \\
Control & $856 \pm 24$ & $131 \pm 12$ & $311 \pm 41$ \\
RRS & $757 \pm 27$ & $118 \pm 5$ & $342 \pm 4$ \\
CVS & $791 \pm 29$ & & \\
SHR & & $91 \pm 5$ & $185 \pm 23$ \\
Control & $820 \pm 56$ & $81 \pm 5 \#$ & $175 \pm 16 \#$ \\
RRS & $668 \pm 23^{*}$ & $86 \pm 6$ & $198 \pm 23$ \\
CVS & $720 \pm 39$ & & \\
\hline
\end{tabular}

Data are expressed as mean \pm SEM ( $n=7-9 /$ group).

${ }^{*} \mathrm{P}<0.05$ vs respective control group.

${ }^{\#} \mathrm{P}<0.05$ vs normotensive groups regardless of stress exposure.

Two-way ANOVA followed by Bonferroni post hoc test.

indicated an effect of strain $\left.\left(\mathrm{F}_{(} 1,41\right)=5, \mathrm{P}<0.02\right)$ and stress $\left(\mathrm{F}_{(2,41)}=6, \mathrm{P}<0.003\right)$, but without a stress $\mathrm{x}$ strain interaction $\left(F_{(2,41)}=0.3, P>0.05\right)$. Analysis of relative heart weight indicated a strain effect $\left(\mathrm{F}_{(} 1,41_{1}=9, \mathrm{P}<0.004\right)$, but without stress effect $\left(\mathrm{F}_{(2,41)}=1, \mathrm{P}>0.05\right)$ and stress $\mathrm{x}$ strain interaction $\left(\mathrm{F}_{(2,41)}=2\right.$, $P>0.05)$.

\subsubsection{Adrenals weight}

The SHR rats presented lower adrenal glands weight regardless of stress exposure (Table 1). Analysis of relative adrenals weight (adrenals weight/body weight at $10^{\text {th }}$ day) indicated that RRS $(\mathrm{P}<0.05)$ and CUS $(\mathrm{P}<0.05)$ caused hypertrophy of the gland in normotensive rats (Fig. 1C). The analysis of the absolute values of adrenal weight indicated an effect of strain $\left(\mathrm{F}_{(1,41)}=29, \mathrm{P}<0.0001\right)$, but without effect of stress $\left(\mathrm{F}_{(2,41)}=0.1, \mathrm{P}>0.05\right)$ and strain $\mathrm{x}$ stress interaction $\left(\mathrm{F}_{(} 2,41_{1}=0.9, \mathrm{P}>0.05\right)$. The analysis of relative adrenal weight indicated a significant effect of strain $\left(\mathrm{F}_{(} 1,41_{)}=5, \mathrm{P}<0.04\right)$ and stress $\left(\mathrm{F}_{(2,41)}=4, \mathrm{P}<0.02\right)$, but without a stress $\mathrm{x}$ strain interaction $\left.\left(\mathrm{F}_{(} 2,41\right)=0.2, \mathrm{P}>0.05\right)$.

\subsubsection{Thymus weight}

SHR rats had lower values of absolute and relative weight (thymus weight/body weight at $10^{\text {th }}$ day) of the thymus regardless of stress exposure (Table 1 and Fig. 1C). Analysis of the absolute thymus weight indicated a strain effect $\left.\left(\mathrm{F}_{(} 1,41\right)=51, \mathrm{P}<0.0001\right)$, but without effect of stress $\left(\mathrm{F}_{(2,41)}=0.6, \mathrm{P}>0.05\right)$ and strain $\mathrm{x}$ stress interaction $\left.\left(\mathrm{F}_{(} 2,41\right)=0.01, \mathrm{P}>0.05\right)$. The analysis of the relative thymus weight also indicated an effect of strain $\left.\left(\mathrm{F}_{(} 1,41\right)=73, \mathrm{P}<0.0001\right)$, but without effect of stress $\left(\mathrm{F}_{(2,41)}=2, \mathrm{P}>0.05\right)$ and strain $\mathrm{x}$ stress interaction $\left(\mathrm{F}_{(} 2,41_{)}=2, \mathrm{P}>0.05\right)$.

\subsubsection{Plasma corticosterone}

Analysis of baseline plasma corticosterone concentration indicated 

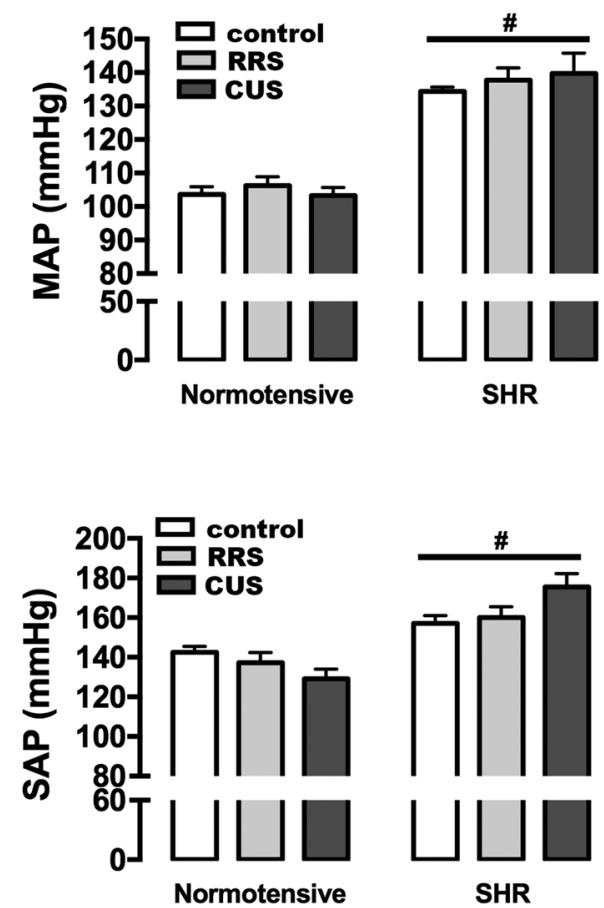

that SHR in all experimental groups presented higher values in relation to normotensive groups (Fig.1C). Furthermore, RRS and CUS increased plasma corticosterone levels in both normotensive (RRS: $\mathrm{P}<0.05$, ECV: $\mathrm{P}<0.05$ ) and SHR rats (RRS: $\mathrm{P}<0.01$, CUS: $\mathrm{P}<0.05$ ) (Fig. 1C). The two-way ANOVA indicated an effect of strain $\left.\left(\mathrm{F}_{(} 1,32\right)=96, \mathrm{P}<0.0001\right)$ and stress $\left(\mathrm{F}_{(2,32)}=9, \mathrm{P}<0.0009\right)$, but without a strain $\mathrm{x}$ stress interaction $\left(\mathrm{F}_{(2,32)}=0.2, \mathrm{P}>0.05\right)$ (Fig. 1C).

\subsection{Effects of CUS and RRS in normotensive and SHR rats on basal cardiovascular parameters}

SHR rats had higher values of MAP $(\mathrm{P}<0.05)$, SAP $(\mathrm{P}<0.05)$, and DAP $(\mathrm{P}<0.05)$ regardless of stress exposure (Fig. 2). Analysis of MAP, DAP and SAP indicated an effect of strain (MAP: $\left.F_{(} 1,41\right)=149$, $\mathrm{P}<0.0001 ;$ DAP: $\mathrm{F}_{(} 1,41_{1}=87, \mathrm{P}<0.0001 ;$ SAP: $\mathrm{F}_{(} 1,41_{1}=48$, $\mathrm{P}<0.0001$ ), but without effect of stress (MAP: $F_{(2,41)}=0.4$,

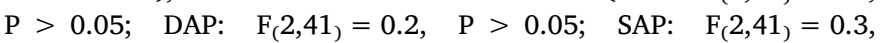
$P>0.05)$. Analysis of SAP $\left.\left(F_{2} 2,41\right)=5, P<0.01\right)$, but not of MAP $\left(\mathrm{F}_{(} 2,41_{)}=0.4, \mathrm{P}>0.05\right)$ and DAP $\left(\mathrm{F}_{(2,41)}=0.2, \mathrm{P}>0.05\right)$, indicated a strain $\mathrm{x}$ stress interaction.

RRS increased baseline HR in normotensive $(\mathrm{P}<0.001)$ and SHR $(\mathrm{P}<0.05)$ rats (Fig. 2). Baseline HR analysis indicated an effect of stress $\left(\mathrm{F}_{(2,41)}=12, \mathrm{P}<0.0001\right)$ and strain $\left(\mathrm{F}_{(1,41)}=9, \mathrm{P}<0.003\right)$, but without a stress $\mathrm{x}$ strain interaction $\left(\mathrm{F}_{(2,41)}=1, \mathrm{P}>0.05\right)$.

3.3. Effects of CUS and RRS in normotensive and SHR rats on intrinsic $H R$ and cardiac autonomic activity

\subsubsection{Intrinsic $H R$}

Analysis of the HR values after combined treatment with propranolol and methylatropine (i.e., intrinsic HR) indicated that CUS increased values in normotensive rats $(P<0.05)$, but not in SHR rats $(\mathrm{P}>0.05)$ (Fig. 3). Analysis indicated an effect of stress $\left(F_{(} 2,41\right)=5$, $\mathrm{P}<0.01)$ and strain $\left.\left(\mathrm{F}_{(} 1,41\right)=15, \mathrm{P}<0.0004\right)$, but without a stress $\mathrm{x}$ strain interaction $\left(\mathrm{F}_{(2,41)}=3, \mathrm{P}<0.05\right)$.

\subsubsection{Cardiac sympathetic activity}

Analysis of the HR change induced by intravenous administration of

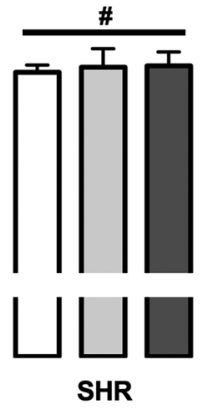

Fig. 2. Mean arterial pressure (MAP), systolic arterial pressure (SAP), diastolic arterial pressure (DAP) and heart rate (HR) in normotensive and SHR rats control (white bars) and subjected to RRS (light grey bars) or CUS (dark grey bars). The bars represent the mean \pm SEM. $* \mathrm{P}<0.05$ vs respective control group, $\# \mathrm{P}<0.05$ vs control groups regardless of stress exposure. Two-way ANOVA followed by Bonferroni post-hoc test ( $n=7-9$ /group). propranolol indicated that RRS increased the sympathetic activity to the heart in both normotensive $(\mathrm{P}<0.05)$ and SHR $(\mathrm{P}<0.001)$ rats (Fig. 3). Analysis indicated a stress effect $\left(F_{(}(2,41)=15, P<0.0001\right)$, but without influence of strain $\left(\mathrm{F}_{(} 1,41_{1}=3, \mathrm{P}>0.05\right)$ and stress $\mathrm{x}$ strain interaction $\left(\mathrm{F}_{(2,41)}=2, \mathrm{P}>0.05\right)$.

\subsubsection{Cardiac parasympathetic activity}

Analysis of the HR change induced by intravenous administration of methylatropine indicated that CUS increased the cardiac parasympathetic activity in normotensive rats $(\mathrm{P}<0.001)$, but not in SHR rats $(\mathrm{P}>0.05)$ (Fig. 3). The analysis indicated an effect of stress $\left(\mathrm{F}_{(2,41)}=18, \mathrm{P}<0.0001\right)$ and strain $\left(\mathrm{F}_{(} 1,41_{1}=5, \mathrm{P}<0.03\right)$, as well as a strain $\mathrm{x}$ stress interaction $\left(\mathrm{F}_{(2,41)}=4, \mathrm{P}<0.02\right)$.

\subsection{Effects of CUS and RRS in normotensive and SHR rats in baroreflex function}

Results of baroreflex activity analysis are presented in Fig. 4. Nonlinear regression analysis of baroreflex activity indicated that SHR females had lower values for gain $(\mathrm{G})(\mathrm{P}<0.05)$, lower plateau $\left(\mathrm{P}_{1}\right)$ $(\mathrm{P}<0.05)$, upper plateau $\left(\mathrm{P}_{2}\right)(\mathrm{P}<0.05)$ and $\mathrm{HR}$ range $(\mathrm{P}<0.05)$ regardless of stress exposure. Besides, RRS increased $\mathrm{P}_{2}$ in SHR $(\mathrm{P}<0.05)$, but not in normotensive animals $(\mathrm{P}>0.05)$.

Analysis of $G$ and $H R$ range indicated a strain effect (G: $\mathrm{F}_{(1,41)}=30, \mathrm{P}<0.0001$; HR range: $\left.\mathrm{F}_{(1,41)}=26, \mathrm{P}<0.0001\right)$, but without effect of stress $\left(\mathrm{G}: \mathrm{F}_{(} 2,41\right)=0.3, \mathrm{P}>0.05$; HR range: $\left.\mathrm{F}_{(} 2,41_{)}=01, \mathrm{P}>0.05\right)$ and strain $\mathrm{x}$ stress interaction $\left(\mathrm{G}: \mathrm{F}_{(} 2,41_{1}=2\right.$, $P>0.05$; HR range: $\left.\left.F_{(} 2,41\right)=3, P>0.05\right)$. Analysis of $P_{1}$ indicated an effect of strain $\left.\left(\mathrm{F}_{(} 1,41\right)=36, \mathrm{P}<0.0001\right)$ and stress $\left(\mathrm{F}_{(2,41)}=4\right.$, $\mathrm{P}<0.04)$, but without a strain $\mathrm{x}$ stress interaction $\left(\mathrm{F}_{(2,41)}=1\right.$, $P>0.05)$. Analysis of $P_{2}$ indicated effect of strain $\left(F_{(} 1,41\right)=54$, $\mathrm{P}<0.0001)$ and a strain $\mathrm{x}$ stress interaction $\left(\mathrm{F}_{(2,41)}=6, \mathrm{P}<0.008\right)$, but without a stress effect $\left(\mathrm{F}_{(2,41)}=1, \mathrm{P}>0.05\right)$. Analysis of $\mathrm{BP}_{50}$ did not indicate effect neither strain $\left(\mathrm{F}_{(} 1,41_{)}=0.3, \mathrm{P}>0.05\right)$ nor stress $\left.\left(\mathrm{F}_{(} 1,41\right)=0.2, \mathrm{P}>0.05\right)$.

Table 2 summarizes the main findings documented in the present study. 


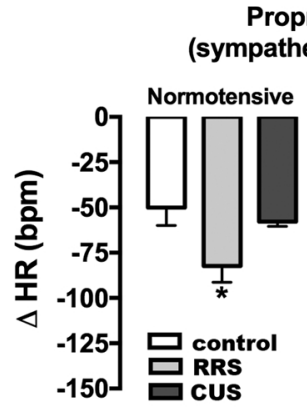

Propranolol sympathetic activity) SHR

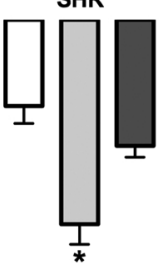

Methylatropine (parasympathetic activity)
Propranolol + Methylatropine (intrinsic HR)
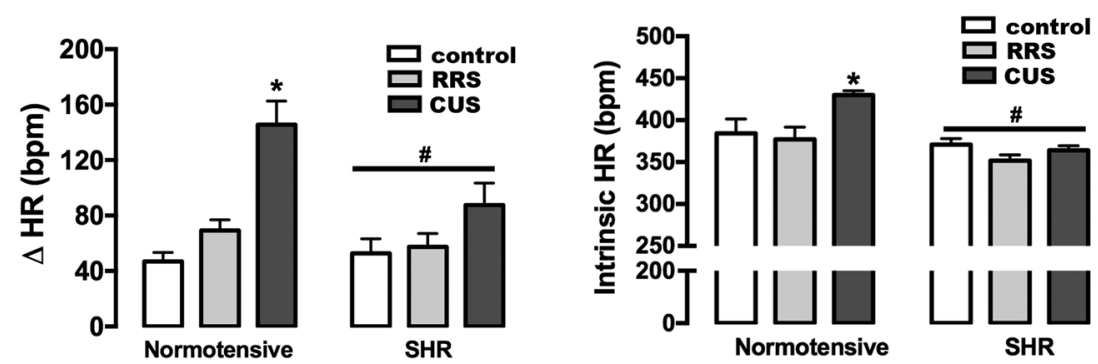

Fig. 3. Cardiac autonomic activity and intrinsic HR in normotensive and SHR rats control (white) and subjected to RRS (light grey) or CUS (dark grey). (Left) HR change $(\Delta \mathrm{HR})$ evoked by systemic administration of the $\beta$-adrenoceptor antagonist propranolol (sympathetic activity). (Middle) $\Delta$ HR evoked by systemic administration of the muscarinic cholinergic receptor antagonist methylatropine (parasympathetic activity). (Right) HR values after combined treatment with methylatropine and propranolol (intrinsic HR). The bars represent the mean \pm SEM. *P $<0.05$ vs respective control group, \#P $<0.05$ vs control groups regardless of stress exposure. Two-way ANOVA followed by Bonferroni post-hoc test $(\mathrm{n}=7-9 /$ group $)$.

\section{Discussion}

The results reported here are the first to provide evidence of the impact of chronic stressors in autonomic activity and baroreflex function in female hypertensive animals. This study is also the first to evaluate the interplay between hypertension and different chronic stress regimens in neuroendocrine and cardiovascular functions.

\subsection{Influence of hypertension}

Both chronic stress protocols decreased body weight gain in normotensive Wistar rats and SHR. A previous study identified a similar decrease in body weight gain and food intake in different strains of male normotensive rats (Brown Norway, Fischer, Lewis and Wistar Kyoto-WKY) and SHR exposed to immobilization stress for 14 days
(Gómez et al., 1996). These results support our findings and indicate that the similar effect of homotypic stressors on body weight in SHR and normotensive Wistar animals does not seem to depend on sex. However, the effects of stress on body weight in SHR rats seem to depend on the stress paradigm. For instance, decrease of body weight caused by social defeat stress was lower in SHR relative to normotensive Lewis rats (Berton et al., 1997), while the effect of agglomeration stress was more pronounced in SHR versus normotensive WKY rats (Slezak et al., 2014). To the best of our knowledge, our data are the first to investigate the effects of CUS protocols on body weight of SHR animals.

Our findings of adrenal gland hypertrophy selectively in normotensive Wistar rats corroborates with evidence from studies investigating the effects of immobilization stress and social defeat in SHR and normotensive rats (either Brown Norway, Fischer, Lewis or WKY)
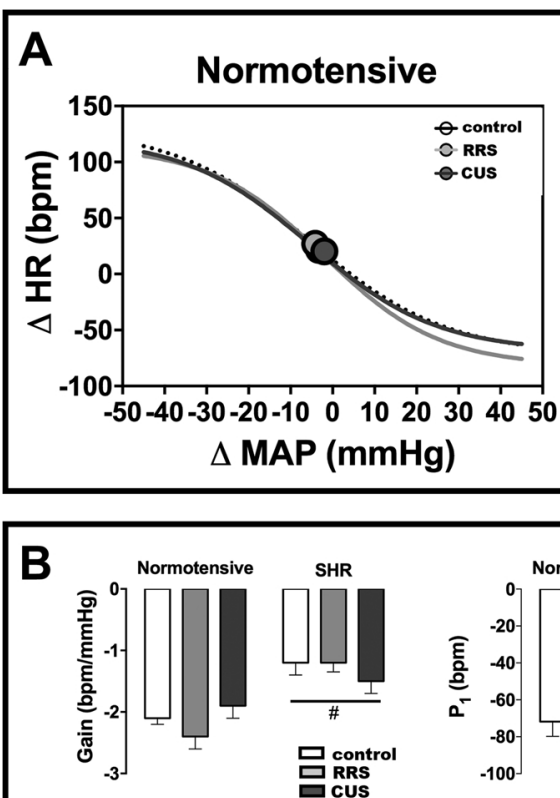

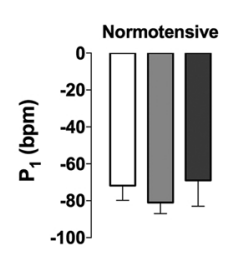

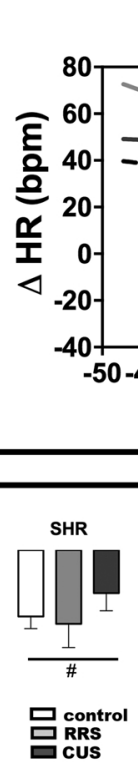
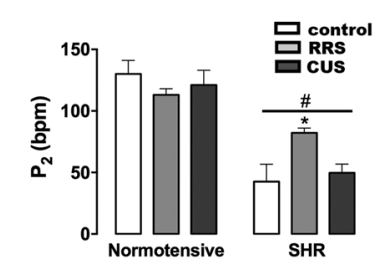

SHR

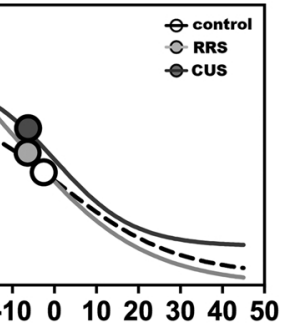

$\triangle$ MAP (mmHg)
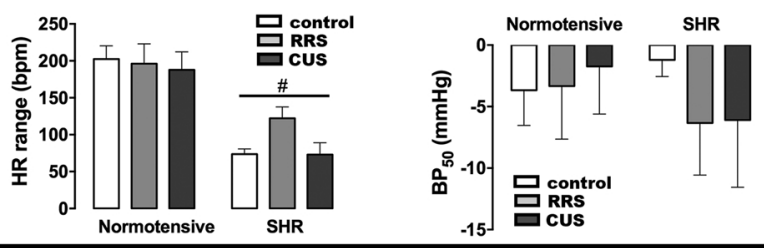

Fig. 4. Analysis of baroreflex activity in normotensive and SHR rats control and subjected to RRS or CUS. (A) Nonlinear regression analysis of the baroreflex correlating mean arterial pressure change ( $\triangle \mathrm{MAP}$ ) evoked by intravenous infusion of phenylephrine and sodium nitroprusside and the reflex $\mathrm{HR}$ response $(\Delta \mathrm{HR})$ in normotensive and SHR rats control (white symbol, dashed curve) and subjected to RRS (light grey symbol, light grey curve) or CUS (dark grey symbol, dark grey curve). Symbols on sigmoid curves indicate the $\mathrm{BP}_{50}$. (B) Parameters derived from nonlinear regression analysis of the baroreflex in normotensive and SHR rats control (white) and subjected to RRS (light grey) or CUS (dark grey). The bars represent the mean \pm SEM. ${ }^{*} \mathrm{P}<0.05$ vs respective control group, \#P $<0.05$ vs control groups regardless of stress exposure. Two-way ANOVA followed by Bonferroni post-hoc test ( $\mathrm{n}=7-9 /$ group). 
Table 2

Summary of the effects of RRS and CUS in normotensive and SHR rats.

\begin{tabular}{|c|c|c|c|c|}
\hline & $\begin{array}{l}\text { RRS } \\
\text { normotensive }\end{array}$ & $\begin{array}{l}\text { CUS } \\
\text { normotensive }\end{array}$ & RRS SHR & CUS SHR \\
\hline \multicolumn{5}{|l|}{ Somatic parameters } \\
\hline Body weight ${ }^{\mathrm{a}}$ & $\downarrow$ & $\downarrow$ & $\downarrow$ & $\downarrow$ \\
\hline Heart weight ${ }^{\mathrm{a}}$ & - & - & - & - \\
\hline Adrenal weight ${ }^{\mathrm{a}}$ & $\uparrow$ & $\uparrow$ & - & - \\
\hline Thymus weight ${ }^{\mathrm{a}}$ & - & - & - & - \\
\hline \multicolumn{5}{|l|}{ HPA axis } \\
\hline Corticosterone ${ }^{\mathrm{a}}$ & $\uparrow$ & $\uparrow$ & $\uparrow$ & $\uparrow$ \\
\hline \multicolumn{5}{|c|}{ Cardiovascular baseline } \\
\hline Arterial pressure ${ }^{\text {a }}$ & - & - & - & - \\
\hline$H R$ & $\uparrow$ & - & $\uparrow$ & - \\
\hline \multicolumn{5}{|l|}{ Autonomic activity } \\
\hline $\begin{array}{l}\text { Sympathetic } \\
\text { activity }\end{array}$ & $\uparrow$ & - & $\uparrow$ & - \\
\hline Vagal activity & - & $\uparrow$ & - & - \\
\hline Intrinsic HR & - & $\uparrow$ & - & - \\
\hline $\begin{array}{l}\text { Baroreflex } \\
\text { bradycardia }^{\text {a }}\end{array}$ & - & - & - & - \\
\hline $\begin{array}{l}\text { Baroreflex } \\
\text { tachycardia }^{a}\end{array}$ & - & - & $\uparrow$ & - \\
\hline
\end{tabular}

Up or down arrows indicate significant increase or decrease, respectively.

a Hypertension effect identified by comparing control groups.

(Berton et al., 1997; Gómez et al., 1996). Nevertheless, differences in thymus weight identified in the present study between SHR and normotensive Wistar rats can be influenced by sex. In this sense, Berton et al (1997) reported higher values of thymus weight in male SHR versus male normotensive Lewis rats. This discrepancy is possibly related to the absence of differences in plasma corticosterone between SHR and normotensive Lewis rats (Berton et al., 1997), which contrasts with the higher levels of this hormone identified in the present study in SHR in relation to the normotensive Wistar rats.

Both stress protocols increased plasma corticosterone levels in normotensive Wistar rat and SHR. Despite the higher values of corticosterone observed in SHR, the increase caused by stress protocols in normotensive Wistar rat and SHR was similar. The results reported in this study are the first to provide evidence of the effect of CUS and RRS on plasma corticosterone levels in SHR. However, higher increase in basal plasma corticosterone levels in SHR relative to normotensive Lewis rats was identified following either 8-week daily exposure to a new environment or to treadmill exercise (Duclos et al., 2001). The increase in plasma corticosterone evoked by 14 days of immobilization stress was also higher in SHR versus WKY rats (Duclos et al., 2001; Gómez et al., 1996). In addition, other studies comparing normotensive rats (either Lewis, Wistar or WKY) and SHR did not identify effect on basal corticosterone levels in any strain following either 7 sessions of social defeat, 14 days of agglomeration stress or 21 days of social isolation in none of the strains (Berton et al., 1997; Djordjevic et al., 2007; Slezak et al., 2014). Together with the findings reported in the present study, these results suggest that the effect of stress on basal corticosterone levels in SHR is related to the type of chronic stressor - though RRS and CUS have similar effects. However, we cannot to exclude the possibility that the differences are also due to sexual dimorphisms. For instance, with the exception of the study by Slezak et al (2014), all other previous studies investigated the effects of the stressors in male SHR (Berton et al., 1997; Djordjevic et al., 2007; Duclos et al., 2001; Gómez et al., 1996). Accordingly, a previous study comparing male and female normotensive Wistar rats identified increase in plasma corticosterone level selectively in females exposed to either RRS or CUS (Vieira et al., 2018).

Previous studies have consistently demonstrated that cardiovascular responses observed during acute stress sessions are more pronounced in SHR relative to normotensive rats (either WKY or Sprague-Dawley) (Casto and Printz, 1990; Knardahl and Hendley, 1990; McCarty, 1983;
McDougall et al., 2005, 2000; van den Buuse et al., 2001; Zhang and Thorén, 1998). However, the effects of exposure to chronic stress protocols on cardiovascular function and autonomic activity in SHR are still poorly understood. We observed that RRS increased basal HR and sympathetic activity in both normotensive Wistar rats and SHR. CUS increased the parasympathetic activity in normotensive Wistar rats, but a consequent change in HR baseline was buffered by an increase in intrinsic HR. Previous studies in male normotensive Wistar and Sprague-Dawley rats identified a sympathetically-mediated resting tachycardia without changes in intrinsic HR following exposure to CUS protocols (Duarte et al., 2015; Grippo et al., 2002). However, to the best of our knowledge, present study is the first to identify an effect of CUS in parasympathetic activity and intrinsic HR in female rats. Regarding the RRS, our results contrast with previous studies comparing male SHR and male normotensive WKY rats in which they did not identify changes in any strain on blood pressure and HR baseline following exposure to 10 daily sessions of restraint stress (McDougall et al., 2005, 2000). A possibility would be an influence of sex on the effects of RRS on cardiovascular function and autonomic activity. However, a recent study from our group indicated increase in baseline HR and sympathetic activity in both male and female normotensive Wistar rats exposed to the same protocol of RRS used in the present study (Vieira et al., 2018). Therefore, further studies are necessary to investigate the influence of sex in effects of RRS on cardiovascular function of SHR rats.

The influence of pre-existing hypertension on impact of chronic stressors was evidenced mainly on the cardiovascular changes in the present study. For instance, increase of parasympathetic tone to the heart is proposed as an important cardioprotective response (Carnevali and Sgoifo, 2014). Therefore, the CUS-evoked increase in parasympathetic tone to the heart in normotensive Wistar rats might constitute an important adaptive response counteracting changes that contribute to heart diseases. In this sense, the absence of this response in SHR might indicate a vulnerability of this strain to cardiac effects of CUS. Besides, exacerbated tachycardic responses are proposed as a risk factor for myocardial ischemia and sudden death (Dyer et al., 1980; Palatini et al., 2011), so that increased reflex tachycardia identified in the present study in SHR, but not in normotensive Wistar rats, subjected to RRS may also constitute an evidence of vulnerability of the hypertensive animals.

\subsection{Influence of stress type}

Previous studies comparing RRS versus CUS have reported that somatic responses (e.g., adrenal hypertrophy and thymus atrophy) and changes in HPA axis activity are observed mainly after exposure to the latter, whereas protocols involving the repeated exposure to the same stressor minimally affect these parameters (Haile et al., 2001; Magariños and McEwen, 1995; Marin et al., 2007; Pastor-Ciurana et al., 2014). The results obtained in the present study of adrenal hypertrophy and increase in plasma corticosterone concentration caused by both chronic stressors contrast with these previous findings. However, it is important to note that evidence of differences between homotypic and heterotypic stressors were mainly obtained in male animals. In this sense, habituation of the HPA axis normally observed upon repeated exposure to the same stressor is impaired in females (Bhatnagar et al., 2005; Chadda and Devaud, 2005; Doremus-Fitzwater et al., 2009; Galea et al., 1997). The reduced habituation process may explain the corticosterone response to RRS in females, since it is proposed as an important adaptive mechanism minimizing the impact of stress (Crestani, 2016; Herman, 2013; McCarty, 2016). In addition, decreased negative feedback regulation of the HPA axis (Xing et al., 2013) and HPA axis hyper-responsiveness during aversive threats (Doremus-Fitzwater et al., 2009; Galea et al., 1997; Handa et al., 1994; Iwasaki-Sekino et al., 2009; Mitsushima et al., 2003; Rivier, 1999) may also account to plasma corticosterone increase evoked by chronic stressors in females. Regarding the influence of chronic stress protocols on body weight 
gain, our findings are in line with previous studies that reported similar decrease following exposure to either CUS or RRS (Duarte et al., 2015; Flak et al., 2011; Magariños and McEwen, 1995; Vieira et al., 2018; Vyas et al., 2002; Yoon et al., 2014).

Recent studies in male normotensive Wistar rats comparing RRS and CUS have demonstrated similar resting tachycardia, increase in cardiac sympathetic activity, and baroreflex impairment following exposure to either stressor (Costa-Ferreira et al., 2016; Duarte et al., 2015; Vieira et al., 2018). However, the results reported in the present study showed that RRS, but not CUS, increased baseline HR and sympathetic activity in both strains, besides increasing baroreflex tachycardia selectively in SHR animals. These findings are in line with recent results from our laboratory in which we observed a vulnerability of female normotensive Wistar rats to cardiovascular and autonomic effects of RRS, and a resilience to the cardiovascular effects of CUS (Vieira et al., 2018). The idea of protective mechanisms in females for the cardiovascular effects of CUS is further supported by recent reports that CUS-evoked vascular dysfunctions were less pronounced in females compared to males (Brooks et al., 2018; Stanley et al., 2014). The increase in cardiac parasympathetic activity following exposure to CUS observed in the present study also provides evidence of a resilience of females to impact of this stressor on cardiovascular function, since as stated above increase in this autonomic branch is proposed as an important cardioprotective response (Carnevali and Sgoifo, 2014).

In summary, present findings indicate an influence of pre-existing hypertension and stressor type in impact of chronic stressors. Influence of the paradigm of stress was identified on deleterious cardiovascular effects, as these changes were evoked selectively by RRS, and both rat strains were resilients to the CUS effects. Vulnerability of hypertensive animals were evidenced by the absence of adaptive cardiovascular responses such as CUS-evoked increase in cardiac parasympathetic activity, as well as by an increase of baroreflex tachycardia in SHR animals subjected to RRS. The somatic and HPA axis changes were overall independent of the chronic stress regimen and hypertension.

\section{Conflicts of interest}

None.

\section{Acknowledgments}

The authors wish to thank Elisabete Z.P. Lepera and Rosana F.P. Silva for technical assistance. This work was supported by grants from FAPESP (grant \# 2015/05922-9 and 2017/19249-0), CNPq (grants \# 456405/2014-3) and Scientific Support and Development Program of School of Pharmaceutical Sciences (UNESP). CCC is a CNPq research fellow (process \# 305583/2015-8).

\section{References}

Al'Absi, M., Lovallo, W.R., McKey, B.S., Pincomb, G.A., 1994. Borderline hypertensives produce exaggerated adrenocortical responses to mental stress. Psychosom. Med. 56, 245-250. https://doi.org/10.1097/00006842-199405000-00011.

Almeida, J., Duarte, J.O., Oliveira, L.A., Crestani, C.C., 2015. Effects of nitric oxide synthesis inhibitor or fluoxetine treatment on depression-like state and cardiovascular changes induced by chronic variable stress in rats. Stress $18,462-474$. https:// doi.org/10.3109/10253890.2015.1038993.

Anishchenko, T.G., Glushkovskaya-Semyachkina, O.V., Berdnikova, V.A., Sindyakova, T.A., 2007. Sex-related differences in cardiovascular stress reactivity in healthy and hypertensive rats. Bull. Exp. Biol. Med. 143, 178-181. https://doi.org/10.1007/ s10517-007-0043-9.

Bernatova, I., Puzserova, A., Dubovicky, M., 2010. Sex differences in social stress-induced pressor and behavioral responses in normotensive and prehypertensive rats. Gen. Physiol. Biophys. 29, 346-354. https://doi.org/10.4149/gpb_2010_04_346.

Berton, O., Aguerre, S., Sarrieau, A., Mormede, P., Chaouloff, F., 1997. Differential effects of social stress on central serotonergic activity and emotional reactivity in Lewis and spontaneously hypertensive rats. Neuroscience $82,147-159$. https://doi.org/10. 1016/S0306-4522(97)00282-0.

Bhatnagar, S., Lee, T.M., Vining, C., 2005. Prenatal stress differentially affects habituation of corticosterone responses to repeated stress in adult male and female rats. Horm.
Behav. 47, 430-438. https://doi.org/10.1016/j.yhbeh.2004.11.019.

Brooks, S.D., Hileman, S.M., Chantler, P.D., Milde, S.A., Lemaster, K.A., Frisbee, S.J., Shoemaker, J.K., Jackson, D.N., Frisbee, J.C., 2018. Protection from vascular dysfunction in female rats with chronic stress and depressive symptoms. Am. J. Physiol. Circ. Physiol. 314, H1070-H1084. https://doi.org/10.1152/ajpheart.00647.2017.

Carnevali, L., Sgoifo, A., 2014. Vagal modulation of resting heart rate in rats: the role of stress, psychosocial factors, and physical exercise. Front. Physiol. 5, 118. https://doi. org/10.3389/fphys.2014.00118.

Casto, R., Printz, M.P., 1990. Exaggerated response to alerting stimuli in spontaneously hypertensive rats. Hypertension 16, 290-300. https://doi.org/10.1161/01.HYP.16.3. 290.

Chadda, R., Devaud, L.L., 2005. Differential effects of mild repeated restraint stress on behaviors and GABAA receptors in male and female rats. Pharmacol. Biochem. Behav. 81, 854-863. https://doi.org/10.1016/j.pbb.2005.06.009.

Costa-Ferreira, W., Vieira, J.O., Almeida, J., Gomes-de-Souza, L., Crestani, C.C., 2016. Involvement of type 1 angiontensin II receptor (AT1) in cardiovascular changes induced by chronic emotional stress: comparison between homotypic and heterotypic stressors. Front. Pharmacol. 7, 262. https://doi.org/10.3389/fphar.2016.00262.

Crestani, C.C., 2016. Emotional stress and cardiovascular complications in animal models: a review of the influence of stress type. Front. Physiol. 7, 251. https://doi.org/10. 3389/fphys.2016.00251.

Crestani, C.C., Tavares, R.F., Alves, F.H.F., Resstel, L.B.M., Correa, F.M.A., 2010. Effect of acute restraint stress on the tachycardiac and bradycardiac responses of the baroreflex in rats. Stress 13, 61-72. https://doi.org/10.3109/10253890902927950.

Djordjevic, J., Vuckovic, T., Jasnic, N., Cvijic, G., 2007. Effect of various stressors on the blood ACTH and corticosterone concentration in normotensive wistar and spontaneously hypertensive Wistar-Kyoto rats. Gen. Comp. Endocrinol. 153, 217-220. https://doi.org/10.1016/j.ygcen.2007.02.004.

Doremus-Fitzwater, T.L., Varlinskaya, E.I., Spear, L.P., 2009. Social and non-social anxiety in adolescent and adult rats after repeated restraint. Physiol. Behav. 97, 484-494. https://doi.org/10.1016/j.physbeh.2009.03.025.

Duarte, J.O., Cruz, F.C., Leão, R.M., Planeta, C.S., Crestani, C.C., 2015. Stress vulnerability during adolescence: comparison of chronic stressors in adolescent and adult rats. Psychosom. Med. 77, 186-199. https://doi.org/10.1097/PSY. 0000000000000141.

Dubey, R., 2002. Sex hormones and hypertension. Cardiovasc. Res. 53, 688-708. https:// doi.org/10.1016/S0008-6363(01)00527-2.

Duclos, M., Martin, C., Malgat, M., Mazat, J.P., Chaouloff, F., Mormède, P., Letellier, T. 2001. Relationships between muscle mitochondrial metabolism and stress-induced corticosterone variations in rats. Pflugers Arch. Eur. J. Physiol. 443, 218-226. https://doi.org/10.1007/s004240100675.

Dyer, A.R., Persky, V., Stamler, J., Paul, O., Shekelle, R.B., Berkson, D.M., Lepper, M., Schoenberger, J.A., Lindberg, H.A., 1980. Heart rate as a prognostic factor for coronary heart disease and mortality: findings in three Chicago epidemiologic studies. Am. J. Epidemiol. 112, 736-749.

Eikelis, N., Van Den Buuse, M., 2000. Cardiovascular responses to Open-Field stress in rats: sex differences and effects of gonadal hormones. Stress 3, 319-334. https://doi. org $/ 10.3109 / 10253890009001137$.

Engi, S.A., Planeta, C.S., Crestani, C.C., 2016. Effect of voluntary ethanol consumption combined with testosterone treatment on cardiovascular function in rats: influence of exercise training. PLoS One 11, e0146974. https://doi.org/10.1371/journal.pone. 0146974.

Flak, J.N., Jankord, R., Solomon, M.B., Krause, E.G., Herman, J.P., 2011. Opposing effects of chronic stress and weight restriction on cardiovascular, neuroendocrine and metabolic function. Physiol. Behav. 104, 228-234. https://doi.org/10.1016/j.physbeh. 2011.03.002.

Galea, L.A., McEwen, B.S., Tanapat, P., Deak, T., Spencer, R.L., Dhabhar, F.S., 1997. Sex differences in dendritic atrophy of CA3 pyramidal neurons in response to chronic restraint stress. Neuroscience 81, 689-697. https://doi.org/10.1016/S03064522(97)00233-9.

Garafova, A., Penesova, A., Cizmarova, E., Marko, A., Vlcek, M., Jezova, D., 2014 Cardiovascular and sympathetic responses to a mental stress task in young patients with hypertension and/or obesity. Physiol. Res. 63, S459-S467.

Gómez, F., Lahmame, A., De Kloet, R., Armario, A., 1996. Hypothalamic-pituitary-adrenal response to chronic stress in five inbred rat strains: differential responses are mainly located at the adrenocortical level. Neuroendocrinology 63, 327-337. https://doi org/10.1159/000126973.

Grippo, A.J., Moffitt, J.A., Johnson, A.K., 2002. Cardiovascular alterations and autonomic imbalance in an experimental model of depression. Am. J. Physiol. - Regul. Integr. Comp. Physiol. 282, R1333-R1341. https://doi.org/10.1152/ajpregu.00614.2001.

Haile, C.N., GrandPre, T., Kosten, Ta., 2001. Chronic unpredictable stress, but not chronic predictable stress, enhances the sensitivity to the behavioral effects of cocaine in rats. Psychopharmacology (Berl). 154, 213-220. https://doi.org/10.1007/ s002130000650.

Handa, R.J., Burgess, L.H., Kerr, J.E., O'Keefe, J.A., 1994. Gonadal steroid hormone receptors and sex differences in the hypothalamo-pituitary-adrenal axis. Horm. Behav. https://doi.org/10.1006/hbeh.1994.1044.

Herman, J.P., 2013. Neural control of chronic stress adaptation. Front. Behav. Neurosci. 7, 61. https://doi.org/10.3389/fnbeh.2013.00061.

Imaki, T., Naruse, M., Harada, S., Chikada, N., Nakajima, K., Yoshimoto, T., Demura, H., 1998. Stress-induced changes of gene expression in the paraventricular nucleus are enhanced in spontaneously hypertensive rats. J. Neuroendocrinol. 10, 635-643. https://doi.org/10.1046/j.1365-2826.1998.00249.x.

Iwasaki-Sekino, A., Mano-Otagiri, A., Ohata, H., Yamauchi, N., Shibasaki, T., 2009. Gender differences in corticotropin and corticosterone secretion and corticotropinreleasing factor mRNA expression in the paraventricular nucleus of the hypothalamus 
and the central nucleus of the amygdala in response to footshock stress or psychological. Psychoneuroendocrinology 34, 226-237. https://doi.org/10.1016/j. psyneuen.2008.09.003.

Knardahl, S., Hendley, E.D., 1990. Association between cardiovascular reactivity to stress and hypertension or behavior. Am. J. Physiol. 259, H248-57.

Koolhaas, J.M., Bartolomucci, A., Buwalda, B., de Boer, S.F., Flügge, G., Korte, S.M. Meerlo, P., Murison, R., Olivier, B., Palanza, P., Richter-Levin, G., Sgoifo, A., Steimer, T., Stiedl, O., van Dijk, G., Wöhr, M., Fuchs, E., 2011. Stress revisited: a critical evaluation of the stress concept. Neurosci. Biobehav. Rev. 35 (5), 1291-1301. https://doi.org/10.1016/j.neubiorev.2011.02.003.

Kudielka, B.M., Kirschbaum, C., 2005. Sex differences in HPA axis responses to stress: a review. Biol. Psychol. 69, 113-132. https://doi.org/10.1016/j.biopsycho.2004.11. 009.

Lenders, J.W.M., Willemsen, J.J., de Boo, T., Lemmens, W.A.J., Thien, T., 1989. Disparate effects of mental stress on plasma noradrenaline in young normotensive and hypertensive subjects. J. Hypertens. 7, 317-323.

Magariños, A.M., McEwen, B.S., 1995. Stress-induced atrophy of apical dendrites of hippocampal CA3c neurons: comparison of stressors. Neuroscience 69, 83-88. https://doi.org/10.1016/0306-4522(95)00256-I.

Marin, M.T., Cruz, F.C., Planeta, C.S., 2007. Chronic restraint or variable stresses differently affect the behavior, corticosterone secretion and body weight in rats. Physiol. Behav. 90, 29-35. https://doi.org/10.1016/j.physbeh.2006.08.021.

Matsukawa, T., Gotoh, E., Uneda, S., Miyajima, E., Shionoiri, H., Tochikubo, O., Ishii, M., 1991. Augmented sympathetic nerve activity in response to stressors in young borderline hypertensive men. Acta Physiol. Scand. 141, 157-165. https://doi.org/10. 1111/j.1748-1716.1991.tb09064.x.

McCarty, R., 1983. Stress, behavior and experimental hypertension. Neurosci. Biobehav. Rev. 7, 493-502. https://doi.org/10.1016/0149-7634(83)90029-5.

McCarty, R., 2016. Learning about stress: neural, endocrine and behavioral adaptations. Stress 19, 449-475. https://doi.org/10.1080/10253890.2016.1192120.

McDougall, S.J., Paull, J.R.A., Widdop, R.E., Lawrence, A.J., 2000. Restraint stress: differential cardiovascular responses in wistar-Kyoto and spontaneously hypertensive rats. Hypertension 35, 126-129. https://doi.org/10.1161/01.HYP.35.1.126.

McDougall, S.J., Lawrence, A.J., Widdop, R.E., 2005. Differential cardiovascular responses to stressors in hypertensive and normotensive rats. Exp. Physiol. 90, 141-150. https://doi.org/10.1113/expphysiol.2004.028308.

Mitsushima, D., Masuda, J., Kimura, F., 2003. Sex differences in the stress-induced release of acetylcholine in the hippocampus and corticosterone from the adrenal cortex in rats. Neuroendocrinology 78, 234-240. https://doi.org/10.1159/000073707.

Palatini, P., Bratti, P., Palomba, D., Bonso, E., Saladini, F., Benetti, E., Casiglia, E., 2011. $\mathrm{BP}$ reactivity to public speaking in stage 1 hypertension: influence of different task scenarios. Blood Press. 20, 290-295. https://doi.org/10.3109/08037051.2011. 566011.

Pastor-Ciurana, J., Rabasa, C., Ortega-Sánchez, J.A., Sanchís-Ollè, M., Gabriel-Salazar, M., Ginesta, M., Belda, X., Daviu, N., Nadal, R., Armario, A., 2014. Prior exposure to repeated immobilization or chronic unpredictable stress protects from some negative sequels of an acute immobilization. Behav. Brain Res. 265, 155-162. https://doi.org/ 10.1016/j.bbr.2014.02.028.
Rivier, C., 1999. Gender, sex steroids, corticotropin-releasing factor, nitric oxide, and the HPA response to stress. Pharmacol. Biochem. Behav. 64, 739-751. https://doi.org/ 10.1016/S0091-3057(99)00148-3.

Roman, O., Seres, J., Pometlova, M., Jurcovicova, J., 2004. Neuroendocrine or behavioral effects of acute or chronic emotional stress in Wistar Kyoto (WKY) and spontaneously hypertensive (SHR) rats. Endocr. Regul. 38, 151-155.

Sarnyai, Z., Bíró, É., Penke, B., Telegdy, G., 1992. The cocaine-induced elevation of plasma corticosterone is mediated by endogenous corticotropin-releasing factor (CRF) in rats. Brain Res. 589, 154-156. https://doi.org/10.1016/0006-8993(92) 91176-F.

Slezak, P., Puzserova, A., Balis, P., Sestakova, N., Majzunova, M., Dovinova, I., Kluknavsky, M., Bernatova, I., 2014. Genotype-related effect of crowding stress on blood pressure and vascular function in young female rats. Biomed. Res. Int. 2014, 413629. https://doi.org/10.1155/2014/413629.

Stanley, S.C., Brooks, S.D., Butcher, J.T., D’Audiffret, A.C., Frisbee, S.J., Frisbee, J.C., 2014. Protective effect of sex on chronic stress- and depressive behavior-induced vascular dysfunction in BALB/cJ mice. J. Appl. Physiol. 117, 959-970. https://doi. org/10.1152/japplphysiol.00537.2014.

Steptoe, A., Kivimäki, M., 2012. Stress and cardiovascular disease. Nat. Rev. Cardiol. 9, 360-370. https://doi.org/10.1038/nrcardio.2012.45.

Toot, J.D., Reho, J.J., Novak, J., Dunphy, G., Ely, D.L., Ramirez, R.J., 2011. Colony social stress differentially alters blood pressure and resistance-sized mesenteric artery reactivity in SHR/y and WKY male rats. Stress 14, 33-41. https://doi.org/10.3109/ 10253890.2010 .491876$.

Trippodo, N.C., Frohlich, E.D., 1981. Similarities of genetic (spontaneous) hypertension. Man and rat. Circ. Res. 48, 309-319. https://doi.org/10.1161/01.RES.48.3.309.

van den Buuse, M., Lambert, G., Fluttert, M., Eikelis, N., 2001. Cardiovascular and behavioural responses to psychological stress in spontaneously hypertensive rats: effect of treatment with DSP-4. Behav. Brain Res. 119, 131-142. https://doi.org/10.1016/ S0166-4328(00)00349-1.

Vieira, J.O., Duarte, J.O., Costa-Ferreira, W., Morais-Silva, G., Marin, M.T., Crestani, C.C., 2018. Sex differences in cardiovascular, neuroendocrine and behavioral changes evoked by chronic stressors in rats. Prog. Neuro-Psychopharmacol. Biol. Psychiatry 81, 426-437. https://doi.org/10.1016/j.pnpbp.2017.08.014.

Vyas, A., Mitra, R., Shankaranarayana Rao, B.S., Chattarji, S., 2002. Chronic stress induces contrasting patterns of dendritic remodeling in hippocampal and amygdaloid neurons. J. Neurosci. 22, 6810-6818 https://doi.org/20026655.

Xing, Y., He, J., Hou, J., Lin, F., Tian, J., Kurihara, H., 2013. Gender differences in CMS and the effects of antidepressant venlafaxine in rats. Neurochem. Int. 63, 570-575. https://doi.org/10.1016/j.neuint.2013.09.019.

Yoon, S.H., Kim, B.H., Ye, S.K., Kim, M.H., 2014. Chronic non-social stress affects depressive behaviors but not anxiety in mice. Korean J. Physiol. Pharmacol. 18 263-268. https://doi.org/10.4196/kjpp.2014.18.3.263.

Zhang, W., Thorén, P., 1998. Hyper-responsiveness of adrenal sympathetic nerve activity in spontaneously hypertensive rats to ganglionic blockade, mental stress and neuronglucopenia. Pflugers Arch. Eur. J. Physiol. 437, 56-60. https://doi.org/10.1007/ s004240050746. 